\title{
How Municipal Development Leaders Experienced Their Professional Role and Responsibility
}

\author{
Mette Sandoff ${ }^{1, *} \&$ Kerstin Nilsson ${ }^{2}$ \\ ${ }^{1}$ Department of Business Administration, School of Business, Economics and Law, University of Gothenburg, \\ Göteborg, Sweden \\ ${ }^{2}$ Institute of Health and Caring Science, The Sahlgrenska Academy, University of Gothenburg, Göteborg, Sweden \\ *Correspondence: Department of Business Administration, School of Business, Economics and Law, University of \\ Gothenburg, Göteborg, Sweden, University of Gothenburg, PO Box 100, SE 40530 Gothenburg, Sweden. Tel: \\ 46-31-786-4491. E-mail: mette.sandoff@gu.se
}

Received: August 18, 2016

Accepted: August 31, $2016 \quad$ Online Published: October 12, 2016

doi:10.5430/mos.v3n4p1

URL: http://dx.doi.org/10.5430/mos.v3n4p1

\begin{abstract}
The purpose of this study has been to explore how municipal development leaders experienced their professional role and responsibility while working to support urban development at development departments in city constituencies in Gothenburg. An explorative approach was used and 18 interviews were conducted and qualitatively analyzed. Development leaders' expertise and their professional contributions were not utilized effectively. Instead of being a force to be reckoned with through their contributions to urban development, their initiatives, professionalism and concern did not lead to any kind of actual decisions or development, but only to feelings of personal resignation. The intention has not been fulfilled of professionally enhancing urban development by employing development leaders at development departments on the city constituency level. The reasons are that the development leaders' work assignment was only vaguely described and that the organizational and managerial structure was inadequately defined. Limitations and shortcomings are discussed in relation to work assignments, organizational structure, professionalization, and urban development work, based on municipal development leaders' experiences of their role and responsibility.
\end{abstract}

Keywords: municipal development leader; professional role; responsibility; explorative approach; qualitative study

\section{Introduction and Purpose}

The urban development of cities is a complex challenge imposing new demands on actors, activities and perspectives. On a municipality level, politicians have to take active steps in order to prepare the organization to meet these new challenges and demands. To face these challenges, the city of Gothenburg (The City of Gothenburg, 2016), introduced a new professional group, development leaders, in 2011. The municipality established a development department in every city constituency, staffed by development leaders and managed by a development manager. Each development leader was responsible for one specific area of expertise. This study focuses on the development leaders' experiences of their role and responsibility in the newly established work function supporting municipal urban development.

The establishment of development departments staffed by development leaders specialized in specified areas of expertise may be viewed as a step towards professionalization, i.e. by introducing professionally structured urban development work to the municipality. Brante discussed this in terms of establishing a "pre-profession" or "wanna-be" profession (Brante, 2010). According to Brante, such intentionally started professional processes can be understood as a response to some kind of need in the society. One of Brante's examples is "developers and implementers of expertise in order to resolve new social problems like environment" (p. 869) (Brante, 2010).

The concept of profession is ambiguous (Molander \& Terum, 2008) and there are numerous ways of defining and characterizing it (Brante, 2005, 2009, 2011, 2013). An inherent problem is, however, that a professional group does not exist in isolation; instead the status of a professional group is dependent upon its specific environment (Brante, 
1988). In this study the specific environment is development departments aiming to support municipal urban development in Gothenburg.

Swedish municipalities have been the focus of several studies (Brorström, 2015; Fred, 2015; Tagesson, Klugman, \& Lindvall Ekström, 2013). However, to our knowledge, no other municipalities in Sweden so far have employed development leaders and established development departments on city constituency level in order to enhance urban development professionally. Studies concerning professional groups specialized in urban development have not been found in the literature review. This has been established by Edman who has studied urban development as a professional field and concluded that urban development is not connected to any one specific occupation (Edman, 2001a, 2001b). He encouraged studies focusing on specific occupations involved in urban development and recommended narrowing down descriptions of role and responsibility. Here is a clear link to this current study and the pertinence of exploring municipal development leaders' experiences of their role and responsibility in urban development. In line with Brante's (Brante, 1988) and Edman's (Edman, 2001a, 2001b) suggestions, professional development is related to the specific environment. Thus empirical findings can contribute to a broader understanding of the role of the municipal development leader.

Accordingly, the purpose of this study has been to explore how municipal development leaders experienced their professional role and responsibility while working to support urban development at development departments in city constituencies in Gothenburg.

\section{Method}

\subsection{Design}

An explorative approach (Patton, 2002) was used since the phenomenon development leaders' experiences of their role and responsibility is unknown.

\subsection{Setting}

The participants in this study, development leaders, are employed in the development departments of three city constituencies. These were selected because they differ from each other demographically - their differences in population give rise to different urban development challenges to tackle. Collectively they represent Gothenburg well. Procedure Documents specify the intentions regarding the role of development departments as well as the work assignment for a development leader. The development leaders must serve and support four operational sections within the municipality. The specified areas of expertise for development leaders are: the European Union, public health, civil dialogue, human rights/equality/diversity, the environment, security, physical urban development and safety (Göteborgs Stad, 2009, 2010a, 2010b, 2010c, 2011). Furthermore, it is postulated that development leaders must have subject knowledge, social competence/skills, leadership, methodological and strategic competence and that they must work in a customer-oriented manner in relation to the operational sections (Göteborgs Stad, 2010b).

\subsection{Participants}

The participants, 18 development leaders, were recruited voluntarily. One participant was male. The mean age was 41, ranging from 28-62 years of age. All the participants were university educated most of them with a master's degree in a subject relevant to their area of expertise. Their average length of professional experience was 13 years with a range of 1-30 years. Ten had held their present position since this new structure was introduced.

\subsection{Data Collection}

Before the interview commenced they gave their written, informed consent, all in accordance with the ethical rules current in Swedish legislation (Act 2003:460 (Amended SFS 2008:192)). The interviews took the form of a conversation but were guided by a semi-structured interview guide with open-ended questions (Patton, 2002) to cover the research purpose. Each interview took place at the respective development leader's office and lasted approximately 60 to 90 minutes. A typical opening question was: "Could you tell me what it means to work as a development leader?"

\subsection{Data Analysis}

The interviews were recorded and transcribed verbatim and then analyzed using qualitative and interpretative analysis with a modified editing style (Crabtree \& Miller, 1992). This means that the interview text was analyzed inductively, based on the purpose, in order to understand the content of the interview text. After reading the whole text to gain an overview of the content, the interviews were imported to the NVIVO 10.0 programme. Then each 
identified unit of meaning was labelled with a code. NVIVO was later used to organize the units of meaning into dimensions that were examined to identify patterns and relationships between them. This interpretative process of analysis resulted in two themes with additional sub-themes. The first author conducted all the interviews but both authors read all the interview texts and cooperated in the analytical work. The process of dividing the data into dimensions and then making comparisons was conducted in an interactive process of discussion between the two authors until agreement was reached. Quotations from the interviews, marked with an identification code, are used to illustrate the findings.

\subsection{Trustworthiness of the Study}

When conducting qualitative research it is important to reflect upon trustworthiness. For that purpose the concepts credibility, confirmability, dependability and transferability are used (Lincoln \& Guba, 1985; Shenton, 2004). Credibility refers to the truth of the findings. Choosing participants with varied experiences increases the possibility of shedding light on the issues from different perspectives (Patton, 2002). In our study the participants varied in age and experience, worked in different constituencies and were responsible for different areas of expertise. The interviews took the form of open conversations, enabling the participants to express themselves freely as well as to reflect in a way they found appropriate. So as not to lose the overall meaning of the study (Graneheim \& Lundman, 2004), the process of analysis started by identifying meaning units based on the purpose of the study. After this dimensions and finally themes and sub-themes were identified. The quotations included represent the voice of the majority rather than the experience of a single participant.

Confirmability is about ensuring that the findings mirror the experiences and ideas of the participants rather than those of the researchers, whose neutrality must be unquestionable (Patton, 2002; Shenton, 2004). The study was conducted on the researchers' initiative and the purpose was to grasp the participants' experiences. There is no reason to doubt that the participants have related experiences that are their own. In order to give the reader a full-scale and meaningful picture the result section is relatively comprehensive.

Dependability is about the consistency of the results and the replicability of the study (Graneheim \& Lundman, 2004; Shenton, 2004). Qualitative explorative research is always dependent upon prevailing conditions and the researcher conducting the study. Both authors are experienced in conducting qualitative research and are well aware of the importance of the researcher's pre-understanding. However, the authors represent two different disciplinary areas: Business Administration/Management and Health Care Pedagogics. This diversity was used as a way to test and question our different interpretations and to be aware of our pre-understandings. Along with individual work, frequently meetings for discussions took place.

Transferability revolves around the applicability of the findings in other contexts (Graneheim \& Lundman, 2004). A narrow but open description of the setting, how participants have been selected, methodological choices and the analytical work gives the reader an opportunity to judge the results' transferability to other contexts.

\section{Findings}

The purpose of this study has been to explore how municipal development leaders experienced their professional role and responsibility while working to support urban development at development departments in city constituencies in Gothenburg. In the analysis of the empirical data two themes with additional sub-themes were identified.

\subsection{How Development Managers Experienced the Role, Mandate and Comprehension of the Assignment}

\subsubsection{The Work Was Primarily a Result of One's Own Initiatives}

The work assignment included a role specification. This document described the mandate and work focus but was otherwise more or less just a formality. According to the participants it was vague about the work efforts expected, how to plan the work in the long and short term and on whose initiative development leaders were supposed to work. The statement below illustrates the discrepancy regarding expectations:

I'm sure there are different expectations. One could ask oneself: what does the role of internal consultant mean and what are the service and support functions? Are we supposed to initiate assignments or are we to deal with those for which we have received an order? (10)

Development leaders' descriptions of their situation revolve around the widespread confusion concerning expectations - what they were supposed to do - and the content - the transformation of their assignment into action. Some of them give examples of a few specified demands from the operational sections, but the majority of the 
descriptions deal with how they themselves had to take the initiative and find relevant work tasks or projects to start up:

We are a support function and the managers in their respective operational sections are supposed to demand assignments from us or ask for whatever they want and order it, but it doesn't work very well. I listen to what people say and take my own initiatives. (14)

When there were few demands from the operational sections, development leaders themselves had to carry out needs analyses in order to serve the assumed needs professionally and appropriately. Some of them worked in this way, whereas some did not as they still expected the operational sections to be more active in raising demands and asking for relevant help in order to cope with their respective assignments. Some describe the operational sections' expectations that they would be more of a professional support function for them. However, it was more common for there to be a confused mixture of expectations as a result of the absence of a clear and specified assignment and a defined strategy for the development leaders' work:

We are supposed to be a support function, but I don't have a manager at the operational section level who gives me assignments/.../we are definitely not a support for any section, but more of support for the manager at city constituency level. But he doesn't give me assignments either - it's more me finding them myself. (12)

\subsubsection{A Vague Work Assignment Created Reactivity}

It is very vague as there is no-one in my city constituency who can tell me how to work and all the constituencies are different/.../the city constituencies are supposed to be as similar as possible, but I still think they are quite different/.../I've had to work out which are my area and my work tasks, but it's all pretty vague.

In line with the quote above, participants mentioned a diffuse and vague work assignment and work situation. What they were to focus on seemed vague to them and likewise who was in a position to take decisions. Some of them coped with this confused situation by taking their own initiatives, focusing on being a professional specialist and giving good advice to those interested in listening to them. A few were able to give some practical examples of how they had contributed professionally due to their expertise. However, prominent in their descriptions is the fact that the diffuseness paralyzed them and detracted from their expected activity as specialists in prioritized areas of expertise. These findings are exemplified in the example below where frustration about the situation dominates:

My problem is that I don't really know what my role is, what it should look like, I compare it to my colleagues and can see that it doesn't look the same but I am also very unsure as to my responsibility and that is where I feel it is not clear. What can I do? What can I demand? (11)

When there were too many uncertainties in terms of whom to serve, what to do, who to cooperate with etcetera, the development leaders said they found it almost impossible to manage the situation. Instead of shouldering the role of being professional experts working in a proactive way, they seemed to be fully occupied with coping with the situation and keeping their heads above water:

I think this position is very fragmented, there are so many ways and sections that I am supposed to work with/.../it is quite a big feat to be both very strategic and also a bit hands on/.../ you are supposed to be the contact person for the citizens, help and support the managers of operational sections dealing with population and at the same time support those planning technical operations with social perspectives. (5)

Another problem raised by the participants involves being excluded from relevant fora considering their expertise. It is almost impossible to work proactively and professionally if one is not invited to take an active part in the early initiatives of a development project in one's own field of knowledge. The result is that development leaders' knowledge was not utilized to the full due to a vague assignment that did not specify which role they were supposed to shoulder:

I am not a support to anyone in the municipality and there are some really important environmental issues dealt with there. So I think that they haven't really thought this through when it comes to an overview of the organization of the development leader position. (12)

\subsubsection{The Work Involved Explaining, Interpreting and Supporting But not Deciding}

To find relevant paths for their daily work in a fairly confused organizational setting, development leaders seemed to define their role as being that of interpreter or mediator, mediating between the overall goal of preparing the city for urban development and practical work within the operational sections. They were able contribute by being discussion partners, explaining and putting problems in a broader context, but it often stopped there. They would have liked to 
have been more operational in terms not only of contributing advice but also making decisions and starting up development actions. As many of them said, they were supposed to be development leaders, but they had no mandate to decide on development actions. Most of what they contributed remained on the rhetorical level but rather less was put into action:

I would say that the title development leader is very misleading when it comes to how the post is designed, because it is not really about developing things in the way a person would normally think. If I say that I am a development leader then you would expect me to work on development but I don't really. (5)

Participants found their own ways of contributing to the overall goal of urban development. Many of them describe having put a lot of effort into finding a good balance between "push and pull" - being a bit bold but at the same time being respectful towards managers with powers of decision:

We can never pursue an issue without support from the hierarchical structure. We can demonstrate a need, we can back it up with statistics and give examples of it but then the decision must be taken by the managers of the operational sections responsible. They are the ones responsible for production and they have the overall responsibility. So if you can get them onboard, things might happen! (16)

The organizational power was somewhere else, above or below the development leaders in the organizational structure. They were between levels, in no-man's land, which was frustrating. If they had been more involved or invited to the top level, they assumed they could have contributed important input to any strategic work.

\subsection{How Development Leaders Experienced Work Execution and Achievements}

\subsubsection{Working Alone without Bridges and Synergies between the Assigned Areas}

All the participants described their work as rather lonely. They described themselves as being knowledgeable in their own area of expertise, but lacking insight into on what and how their development leader colleagues were working. At the same time, they assumed that their respective areas were closely linked to each other, regarding the practical settings and also ways of approaching and dealing with them. They saw possibilities for professional cooperation and synergies and wished that they worked more closely within the department. Their pre-understanding based upon descriptions before starting work as development leaders was that they would work more as a professional team:

Now everyone does their own thing. You have to do something to try to make things work/.../you sit there on your own, you don't give yourself time to ask questions, it's easier to write it yourself, nobody cares. (12)

Teamwork was neither systematically organized nor encouraged. Participants considered that development managers should have been more active in building bridges between different areas of expertise in order to take advantage of development leaders' broad knowledge. Most of them mentioned and appreciated the cooperation between different city constituencies. There was an organized network for each area of expertise. They were expected to meet on a regular basis and at these meetings they shared experiences and work initiatives in order to help each other, not least in the ambition to serve the whole municipality equally.

\subsubsection{A Strategic as well as an Operational Consultative Role}

As already described, development leaders saw themselves as some kind of consultant. They lacked the mandate to make decisions and did not have a budget but they were able to give good advice. This went for all of them but the person they were primarily to serve with expertise differed. Some described their work as being a strategic consultant primarily serving the decision-making body: politicians and managers at the city constituency level. This role enabled development leaders to provide information relevant to strategic decisions regarding urban development. They tried to be ahead of the decision-makers in terms of trying to influence them professionally at an early stage:

Sometimes I can draw attention to problems, what is problematic but also I can be in the forefront and try to contribute something from the city constituency perspective to help so that it won't be problematic in the future. (4)

Others described being more of an operational consultant. They served managers on different levels in the operational sections. This role involved giving advice of a more operational nature. Even though all the participants had the same work assignment and role specification as the basis for their work, their descriptions of their role differed significantly. Many of them described a wish to be more hands-on and to participate in putting ideas into practice, on a strategic or an operational level. Only playing the role of a knowledgeable person, a consultant giving good advice was considered both frustrating and insufficient in terms of utilizing development leaders' expertise. 


\subsubsection{An Administrative and Investigative Role}

Participants described the core of their work as revolving around administrative tasks. They found it hard sometimes to see or grasp the long-term effects of their efforts for the overall goal of municipal urban development. They found that they put a lot of effort into investigating different issues, responding to referrals and following up earlier plans. These tasks were important but at the same time participants questioned if and how their efforts had any effect. They described the absence of feedback on how plans, reports etcetera were used and hopefully made a difference. The gap between being an expert supposedly contributing to urban development and their daily work tasks differed:

But the biggest challenge for these surveys is what they are used for and what is done; there I would say that we are still trying to find a way/.../that is the big challenge that our surveys don't get stuck at this highest level. (16)

Participants were very dedicated in their area of expertise and had a clear perception of its importance. Even so they expressed a feeling of resignation in that their expertise was not properly utilized. There are many descriptions of a role dominated by administrative and investigative tasks but, unfortunately, not very much more. One participant described clearly that her/his post was more or less formed as an administrative role without time or mandate to develop it further:

We work with environmental diplomas that are the core for those of us working on environmental issues. This goes for all the operations and is very administrative. It's more about coordinating operations and arranging meetings. (2)

The descriptions include a sincere concern about not contributing enough professionally or in line with the expectations of others. However, they found those expectations very vague and sometimes conflicting. When asked about the future and the effects if their posts were to be retracted, answers like the following were frequent:

No I don't think that our citizens would notice if we disappeared/.../sometimes it feels as if it doesn't matter what we do because nothing happens. There is no real change. (8)

\section{Discussion}

Development leaders described monitoring the surrounding community in different ways, though they seemed to do this in an unstructured way without any clear idea of how to handle the results. There were no empirical findings showing how the monitoring and analysis would be turned into strategy or strategic work. A probable explanation is that development leaders were seldom invited to the fora where strategic planning was on the agenda. Besides, as a support function they had no mandate to raise their voices or demand anything - which they were all well aware of. Thus it was impossible for them to shoulder professionally the tasks assigned to them, to "develop, implement and teach developmental methods and tools" (Göteborgs Stad, 2011).

Development leaders' descriptions expressed the desire to be able to contribute to municipal urban development (Göteborgs Stad, 2011). They clearly felt knowledgeable and professional and thus able to contribute to the projects in question. But at the same time, it is obvious that development leaders experienced the content and purpose of their role differently. Structure and strategy for their role and instructions on how to carry out their work were apparently lacking. They had to form their working day and actions on their own and had no mandate giving them power of decision. Lack of power leads easily to docility as has been shown in a study on teachers and warders encountering new working conditions (Sandoff \& Widell, 2008, 2009). Docility among development leaders is hard to reconcile with simultaneously being a driving professional force, and contributing with expertise and challenging knowledge.

According to Brante's (Brante, 2010) and Edman's (Edman, 2001a, 2001b) studies of urban development as a professional field, characteristics like significant mandate, power and responsibility as well as respect, confidence and a defined role within the organizational structure are essential for any profession. Such characteristics are apparently lacking in the development leaders' experiences. Their professional capacity and dedication were not taken advantage of. Brante (Brante, 2010) states, that a profession is related to a defined area of expertise. On the basis of the participants' descriptions, clarification is needed of what municipal urban development is. If this had been clarified, their role and work content could have been better structured and the development leaders would have been able to work more professionally. In the Procedure Documents there are descriptions of "working in a customer-oriented manner" in relation to operational sections (Göteborgs Stad, 2010c). However, there is no clear indication in the Procedure Documents of who the customer is supposed to be. This being the case, the notion of customer-orientation was probably ineffectively applied, without professional consistency. The confusion between 
customers' expectations and professionals' expectations was further described in a study on teachers. Teachers experienced the same confusion, frustration and lack of power as the development leaders (Sandoff \& Norén, 2002). One difference shown in these studies is however that being seen as a professional group gave teachers some degree of power and mandate.

Development leaders described their role as a consultancy. They were well aware of the hierarchical structures and that theirs was a support function with no mandate or power of decision. However, they perceived that those in charge of operational sections needed support. When development leaders were asked to assist managers of operational sections, they were able to contribute substantially as facilitators. These findings can be compared to findings on process leaders working in healthcare (Nilsson \& Sandoff, 2015a, 2015b). Process leaders working in a hierarchical organization experienced similar challenges to those of development leaders. They tried hard to facilitate the delivery of good healthcare. The difference between these two studies however is that process leaders' appointment defined their assignment which was to facilitate ongoing processes. Even though they were trapped between different functions in the hierarchical structure, they had a clearly defined assignment. The development leaders' assignment on the other hand lacked this clear definition. They had no mandate to intervene and facilitate when they found it necessary or appropriate in order to support urban development professionally. They realized that they could contribute substantially but needed a "command" from somebody in charge. They felt that their situation outside the hierarchical structure was frustrating and emphasized that this constituted a challenge (Nilsson \& Sandoff, 2015a, 2015b).

Participants sought opportunities to be influential and to use their own expertise to mediate between the needs described by those in the position to decide. They knew they could contribute professional thoughtfulness and intervention before decisions were made and actions were undertaken, if permitted. The need of mediation between different groups within a large public hospital has been discussed in a study and it was argued that good mediation is based on an understanding of situational and contextual circumstances at different organizational levels as well as combining them (Sandoff \& Widell, 2015). Skilful mediators made all the difference in terms of implementing top management strategies. An important difference between the group of mediators (Sandoff \& Widell, 2015) and the group of development leaders is the mandate to make decisions. The hospital HR staff were responsible for getting things working and for implementing the top management strategy in the organization. They developed techniques of skilful mediation and used their mandate and decision-making power to mediate and to implement the strategy. Development leaders had no such mandate or responsibility. They had ideas concerning how to approach predicted challenges but they were only able to facilitate processes and translate goals into actions if somebody in charge asked for their help. They expressed a desire to be able to shoulder their role as development leader, including mediation between designated goals and actions as well as facilitating processes in order to achieve the goals. Although they were frustrated, they did not show any signs of raising their voices in line with Hirschman's terminology (Hirschman, 1970). They did not complain upwards in the hierarchy, which might either be an expression of docility, discussed earlier, perhaps out of fear of losing their jobs, or an expression of resignation due to frustration. Development leaders revealed frustration, but they also revealed a true dedication towards enhancing urban development. We may therefore safely assume that skilled mediators working on top management goals and their implementation via appropriate actions would probably make a great difference to the development of an organization.

The general competence and subject knowledge requirements for developments leaders, described in the Procedure Documents (Göteborgs Stad, 2010b) seem to have been satisfied. All the development leaders were well qualified in their areas of expertise and all were dedicated to their respective areas. However, most of them lacked experience of leading operations including strategic work and implementation processes, which was also an expected qualification (Göteborgs Stad, 2010b). In this case, with deficient leadership qualifications and only vague descriptions of the leadership role and work assignment, supportive management would probably have been vital. Communication skills such as listening and emotional and cultural awareness are important for working effectively with developmental issues in democratic processes (Gruidl \& Hustedde, 2015). Ideally, development department managers should have a broad overview of their respective development department's role and should be able to assist the development leaders with important insights and perspectives. Such a supervisor would probably have been helpful (Ronsten, Andersson, \& Gustavsson, 2005). However, the development managers seem to have been invisible and the development leaders were working very much alone.

Participants stressed that more teamwork between them would have enriched each one's efforts and their individual working situations as well as positively empowering their efforts to enhance urban development. However, there was neither a structure enabling teamwork to be realized in practice nor encouragement from the development department managers' perspective. Similar experiences have been found in a study of a municipal government when 
implementing a change (Seijts \& Roberts, 2011). It was considered important to provide employees with opportunities for participating and being involved in other organization members' work, as well as for contributing their varied competences to the team. The role of development department managers needs to be more clearly defined to give development leaders the chance of having a genuine, goal-directed impact on municipal urban development.

\section{Conclusions}

Lessons learned from this study will probably be of relevance for other municipalities intending to enhance urban development by employing professionals like the development leaders. Also, this study's empirical findings may hopefully contribute to bridging the gap between academics and practitioners (Godschalk, 2014). Godschalk (2014) recommends and wants to see more collaboration between researchers and public planners, among others, when striving towards urban development.

The role of the manager in charge must be clearly defined, both in relation to the overall structure and the professionals' work assignment. Typically for public organizations, support functions like urban development departments are structures outside the main hierarchical order without the supporting staff having any decision power. Without proper management, efforts by supporting professionals will be disconnected from plans, budgets and initiatives decided by politicians or managers within the hierarchical order, and therefore more or less pointless. On the other hand, teamwork organized in a structured way by the manager in charge can contribute positively to the municipality's strivings towards urban development. Synergies enriched by varying areas of expertise should be purposefully promoted in this context. Supportive activities aimed at getting the team to work smoothly must be encouraged. When all aspects are respected and given sufficient space, the organization will benefit greatly from having employed staff with diverse professional competences.

If research-based empirical lessons are not taken into account, in line with Godschalk's (Godschalk, 2014) advice, intentions such as striving towards urban development will turn out rather purposeless. The promotion of urban development must be implemented correctly and it must be based on its users' empirical experiences (Brorström, 2015). The development leaders can be understood as the users. They would have needed managerial guidance regarding how to interpret and comprehend the ideas of the organizational structure and work assignment, including their professional role. Only with this assistance could they have contributed to an effective realization of the ideas. Their experiences will hopefully contribute new understanding, helping to bridge this gap. Otherwise, the case in this study might just turn out to be yet another example of an organization with ideas that look good on paper but are seemingly impossible to put into practice.

\section{References}

Act 2003:460 (Amended SFS 2008:192). The act of ethical trail of research concerning humans. Stockhom: Ministry of Education and Research.

Brante, T. (1988). Sociological Approaches to the Professions. Acta Sociologica, 31(2), 119-142. http://dx.doi.org/10.1177/000169938803100202

Brante, T. (2005). About the concept and the phenomenon profession. [In Swedish]. Tidskrift för praxisnära forskning, (1), 1-13.

Brante, T. (2009). What is a profession? - Theoretical approaches and definitions. [In Swedish]. Borås: Högskolan i Borås.

Brante, T. (2010). Professional Fields and Truth Regimes: In Search of Alternative Approaches. Comparative Sociology, 9(6), 843-886. http://dx.doi.org/10.1163/156913310X522615

Brante, T. (2011). Professions as Science-Based Occupations. Professions \& Professionalism, 1(1), 4-20. doi:http://dx.doi.org/10.7577/pp.v1i1.14

Brante, T. (2013). The Professional Landscape: The Historical Development of Professions in Sweden. Professions \& Professionalism, 3(2), 1-18. http://dx.doi.org/10.7577/pp.558

Brorström, S. (2015). Implementing innovative ideas in a city: good solutions on paper but not in practice? International Journal of Public Sector Management, 28(3), 166-180. http://dx.doi.org/10.1108/IJPSM-11-2014-0137 
Crabtree, B. F., \& Miller, W. L. (1992). Doing Qualitative Research. London: Sage Publications.

Edman, J. (2001a). New Directions in Theorizing the Professions: The Case of Urban Planning in Sweden. Acta Sociologica, 44(4), 301-311. http://dx.doi.org/10.1177/000169930104400402

Edman, J. (2001b). Urban Planning as a Professional Field: A Study of Professional Occupations and their Work. [In Swedish]. Acta Universitatis Upsaliensis, Uppsala.

Fred, M. (2015). Projectification in Swedish municipalities. A case of porous organizations. Scandinavian Journal of Public Administration, 19(2), 49-68.

Godschalk, D. R. (2014). A Planning Life: Bridging Academics and Practice. Journal of the American Planning Association, 80(1), 83-90. http://dx.doi.org/10.1080/01944363.2014.928169

Göteborgs Stad. (2009). Control and management - The city of Gothenburg. [In Swedish]. Göteborg: Göteborgs stad.

Göteborgs Stad. (2010a). Evaluation of different organizational proposals for support functions. [In Swedish]. Göteborg: Göteborgs Stad.

Göteborgs Stad. (2010b). Support functions' task and role. [In Swedish]. Göteborg: Göteborgs Stad.

Göteborgs Stad. (2010c). Utvärdering av olika organisationsförslag för stödfunktionerna. Göteborg: Göteborgs Stad.

Göteborgs Stad. (2011). Development leader - general requirement profile. [In Swedish]. Göteborg: Göteborgs Stad.

Graneheim, U. H., \& Lundman, B. (2004). Qualitative content analysis in nursing research: concepts, procedures and measures to achieve trustworthiness. Nurse Education Today, 24(2), 105-112. http://dx.doi.org/10.1016/j.nedt.2003.10.001

Gruidl, J., \& Hustedde, R. (2015). Towards a robust democracy: the core competencies critical to community developers. Community Development, 46(3), 279-293. http://dx.doi.org/10.1080/15575330.2015.1028082

Hirschman, A. O. (1970). Exit, voice and loyalty: responses to decline in firms, organizations, and states. Cambridge, Mass: Harvard Univiversity Press.

Lincoln, Y. S., \& Guba, E. G. (1985). Naturalistic inquiry. Newbury Park: SAGE Publications.

Molander, A., \& Terum, L. I. (Eds.). (2008). Profession studies. [In Norwegian]. Oslo: Universitetsforlaget.

Nilsson, K., \& Sandoff, M. (2015a). Leading processes of patient care and treatment in hierarchical healthcare organizations in Sweden - process managers' experiences. Leadership in Health Services, 28(2), 135-148. http://dx.doi.org/10.1108/LHS-04-2014-0043

Nilsson, K., \& Sandoff, M. (2015b). Leading processes of patient care and treatment in hierarchical healthcare organizations in Sweden - process managers' experiences. Leadership in Health Services, 28(2), 135-148. http://dx.doi.org/10.1108/LHS-04-2014-0043

Patton, M. Q. (2002). Qualitative research \& evaluation methods. London: SAGE.

Ronsten, B., Andersson, E., \& Gustavsson, B. (2005). Confirming mentorship. Journal of Nursing Management, 13(4), 312-321. http://dx.doi.org/10.1111/j.1365-2934.2005.00541.x

Sandoff, M., \& Norén, L. (2002). When professional standards meet customer orientation - a study of school teachers work situation. [In Swedish]. Nordiske Organisasjonsstudier, 4(3/4), 41-60.

Sandoff, M., \& Widell, G. (2008). Coping with Discipline - Discipline and dilemmas among teachers and warders. International Journal of Sociology and Social Policy, 28(11/12), 548-571. http://dx.doi.org/10.1108/01443330810915189

Sandoff, M., \& Widell, G. (2009). Freedom or docility at work - is there a choice? International Journal of Sociology and Social Policy,, 29(5/6), 201-213. http://dx.doi.org/10.1108/01443330910965741

Sandoff, M., \& Widell, G. (2015). Translating as response to paradoxes - when implementing HRM strategies in service organisations. Zeitschrift fur Personalforschung/German Journal of Research in Human Resource Management, 29(3-4), 303-321. http://dx.doi.org/10.1177/239700221502900308

Seijts, G. H., \& Roberts, M. (2011). The impact of employee perceptions on change in a municipal government. Leadership \& Organization Development Journal, $32(2), \quad 190 \quad-\quad 213$. http://dx.doi.org/10.1108/01437731111113006 
Shenton, A. K. (2004). Strategies for ensuring trustworthiness in qualitative research projects. Education for Information, 22(2), 63-75.

Tagesson, T., Klugman, M., \& Lindvall Ekström, M. (2013). What explains the extent and content of social disclosures in Swedish municipalities' annual reports. Journal of Management \& Governance, 17(2), $217-235$.

The City of Gothenburg. (2016). The Vision. Retrieved from http://www.goteborg2021.com/vision/ 